\title{
Relative mislocalization of briefly presented stimuli in the retinal periphery
}

\author{
JOCHEN MÜSSELER \\ Max Planck Institute for Psychological Research, Munich, Germany \\ A. H. C. VAN DER HELJDEN \\ Leiden University, Leiden, The Netherlands \\ S. H. MAHMUD \\ Dhaka University, Dhaka, Bangladesh \\ and \\ HEINER DEUBEL and SAMAR ERTSEY \\ Ludwig Maximilians University, Munich, Germany
}

\begin{abstract}
We studied the ability to localize flashed stimuli, using a relative judgment task. When observers are asked to localize the peripheral position of a probe with respect to the midposition of a spatially extended comparison stimulus, they tend to judge the probe as being more toward the periphery than is the midposition of the comparison stimulus. We report seven experiments in which this novel phenomenon was explored. They reveal that the mislocalization occurs only when the probe and the comparison stimulus are presented in succession, independent of whether the probe or the comparison stimulus comes first (Experiment 1). The size of the mislocalization is dependent on the stimulus onset asynchrony (Experiment 2) and on the eccentricity of presentation (Experiment 3 ). In addition, the illusion also occurs in an absolute judgment task, which links mislocalization with the general tendency to judge peripherally presented stimuli as being more foveal than they actually are (Experiment 4 ). The last three experiments reveal that relative mislocalization is affected by the amount of spatial extension of the comparison stimulus (Experiment 5) and by its structure (Experiments 6 and 7). This pattern of results allows us to evaluate possible explanations of the illusion and to relate it to comparable tendencies observed in eye movement behavior. It is concluded that the system in charge of the guidance of saccadic eye movements is also the system that provides the metric in perceived visual space.
\end{abstract}

The visual system processes the location of an object as soon as it appears in the visual field. Spatial acuity, measured with various standard methods, is accepted as being of very high precision. It increases from $5 \mathrm{~min}$ of arc at $10^{\circ}$ retinal periphery to better than $1 \mathrm{~min}$ of arc in the fovea. This extremely high acuity is measured with tasks in which the relative position of two spatial features is determined (Badcock \& Westheimer, 1985; Westheimer, 1981). However, these tasks assess acuity with long-presented, stationary targets with high contrastthus, under optimal viewing conditions. They require only local comparisons of simultaneously presented spatial features, which may not be the best indicators for direct absolute localizations (for an overview, see Skavenski, 1990).

We thank Bruce Bridgeman, Asher Cohen, David Rose, and Steven Yantis for helpful comments and suggestions regarding a previous draft of the paper, Birgitt Aßfalg and Sonja Stork for carrying out the experiments, and Marina von Bernhardi and Heidi John for stylistic suggestions. Correspondence concerning this article should be sent to J. Müsseler, MaxPlanck-Institut für Psychologische Forschung, Amalienstr. 33, D-80799 München, Germany (e-mail: muesseler@mpipf-muenchen.mpg.de).
Some studies indicate that absolute localizations of briefly presented stimuli are much poorer than the acuity measures lead one to expect. In these studies of spatial accuracy, participants judge the position of single targets in the periphery, simply by pointing at them with a marker or by assigning them a position on a reference scale. The general finding is that a tendency exists to estimate the position of a target as being more foveal than it actually is (e.g., Mateeff \& Gourevich, 1983; Müsseler \& Aschersleben, 1998; O’Regan, 1984; Osaka, 1977; Rauk \& Luuk, 1980; Rose \& Halpern, 1992; van der Heijden, van der Geest, de Leeuw, Krikke, \& Müsseler, 1999). For example, in O'Regan's study, observers were asked to set a marker to the position of a flashed stimulus. He found that the targets were mislocalized toward the fovea by about $1^{\circ}$ when they were presented at $7.2^{\circ}$ retinal eccentricity.

The localization studies of van der Heijden and coworkers (Hagenaar \& van der Heijden, 1997; van der Heijden et al., 1999) originated in response to errors observed in naming the letter items in the partial-report barprobe task (Averbach \& Coriell, 1961; see also Hagenaar \& van der Heijden, 1995; Hagenzieker, van der Heijden, 
\& Hagenaar, 1990; Mewhort, Campbell, Marchetti, \& Campbell, 1981). When analyzing these errors, Hagenaar and van der Heijden (1997) reported that most of the errors were item exchanges that came from positions adjacent to and on the foveal side of the cue (or, the probe). Such localization errors increased with the temporal separation of letter items and cue. In follow-up experiments, participants were asked either to assign a briefly presented probe to a position on a (fovea-centered and imaginary) scale, which was preexperimentally introduced, or to adjust a cursor to its perceived position after the presentation. Both tasks pointed to a tendency toward foveal mislocalizations of about $10 \%$ (van der Heijden et al., 1999).

In the present context, it is important to note that these foveal mislocalizations were observed mainly with briefly presented stimuli-that is, with stimuli displayed only for a few vertical retraces of a monitor. In a pointing or cursor adjustment task, errors in localization are reduced or absent when presentation times are increased (Adam, Ketelaars, Kingma, \& Hoek, 1993; Adam, Paas, Ekering, \& van Loon, 1995). A comparable finding can be observed in measures of the accuracy of saccades' landing positions with respect to targets in the periphery. This accuracy tends to be high when sufficient time is taken to program the saccade (see, e.g., Kowler \& Blaser, 1995), but saccades reveal increasing mislocalizations under less than optimal conditions (see, e.g., Abrams, Meyer, \& Kornblum, 1989; Aitsebaomo \& Bedell, 1992; Lemij \& Collewijn, 1989). Then, saccades are usually reported to be inaccurate, undershooting the target by about $5 \%-10 \%$ and requiring a corrective saccade to eliminate this error (see, e.g., Aitsebaomo \& Bedell, 1992; Becker, 1972; Deubel, Wolf, \& Hauske, 1982; Henson, 1978). Given the observation that the foveal tendency is also present in the complete absence of eye movements (O'Regan, 1984) and that the size of mislocalization in a psychophysical judgment task is comparable with that with which saccades' landing positions undershoot the target, it follows that the first-perceived visual space seems to be distorted in a foveally oriented manner.

It is important to note that such a distortion of the perceived space cannot simply result from refractions of the optic apparatus, as has been assumed by Osaka (1977). In that case, any position of a perceived target and of an indicator used for judging the position of targets should be subject to distortion and should, therefore, remain unnoticeable. In addition, central compensations for imperfections of the optic apparatus are well known and include eccentric refractions as well (see, e.g., Erkelens, Collewijn, \& Steinman, 1989; Festinger, Burnham, Ono, $\&$ Bamber, 1967; Slotnick, 1969). Since the system is able to adapt to such imperfections (cf. also the adaptation to a prism contact lens; for a recent overview, see Redding \& Wallace, 1992), these kinds of distortions cannot account for the foveal tendency.
In sum, the accuracy of absolute localizations of briefly presented stimuli is rather poor, as compared with acuity measures. This poorness reveals a tendency to estimate the position of a target as being more foveal than it actually is, and this tendency seems to increase with the eccentricity of the target. The restriction of mislocalization to briefly presented stimuli remains completely unsolved.

The present paper is concerned with a localization error that exists in relative judgments but probably originates from the tendency to make a greater number of foveal mislocalizations in absolute judgments. We designed the experimental set-up with the following idea in mind: If a peripherally presented stimulus is perceived as being more foveal than it actually is and if this error increases with the eccentricity of the stimulus (see, e.g., van der Heijden et al., 1999), the spatial extension of that stimulus could be a further critical factor in determining the foveal mislocalization. For example, imagine a spatially extended stimulus of $3^{\circ}$ length presented at $5^{\circ}$ eccentricity. Then, the near-fovea edge at $3.5^{\circ}$ might be perceived with a different localization error, as compared with the far-fovea edge at $6.5^{\circ}$. This should affect the localization of the whole stimulus. It will be localized with respect to the near-fovea or the far-fovea edge, it will be localized in between (for example by "calculating" its mean position), or it will be compressed or stretched, respectively.

In Experiment 1, we examined these possibilities with a relative judgment task. That is, the participants were asked to judge the midposition of the spatially more extended stimulus (the comparison stimulus) with respect to the perceived position of a single less extended stimulus (the probe). In Experiments 2 and 3, basic temporal and spatial characteristics of the experimental procedure were checked-namely, the stimulus onset asynchrony (SOA) between the comparison stimulus and the probe (Experiment 2 ) and the eccentricity of the stimuli (Experiment 3). In Experiment 4, we investigated mislocalization with an absolute judgment task. Finally, in Experiments 5-7, we examined whether and how the localization error was influenced by changes in the configuration of the comparison stimulus.

\section{EXPERIMENT 1}

The basic experimental procedure was as follows. The participants had to judge the position of a probe (the lower square in Figure 1) relative to the midposition of a spatially extended comparison stimulus (the row of five upper squares). The participants' task was to decide whether they saw the probe as being more toward the left or toward the right, relative to the midposition of the extended stimulus.

When the probe and the comparison stimulus are flashed simultaneously, it can be assumed that they are processed in one spatial map as a single stimulus configuration. All the stimulus aspects are subject to a (pos- 


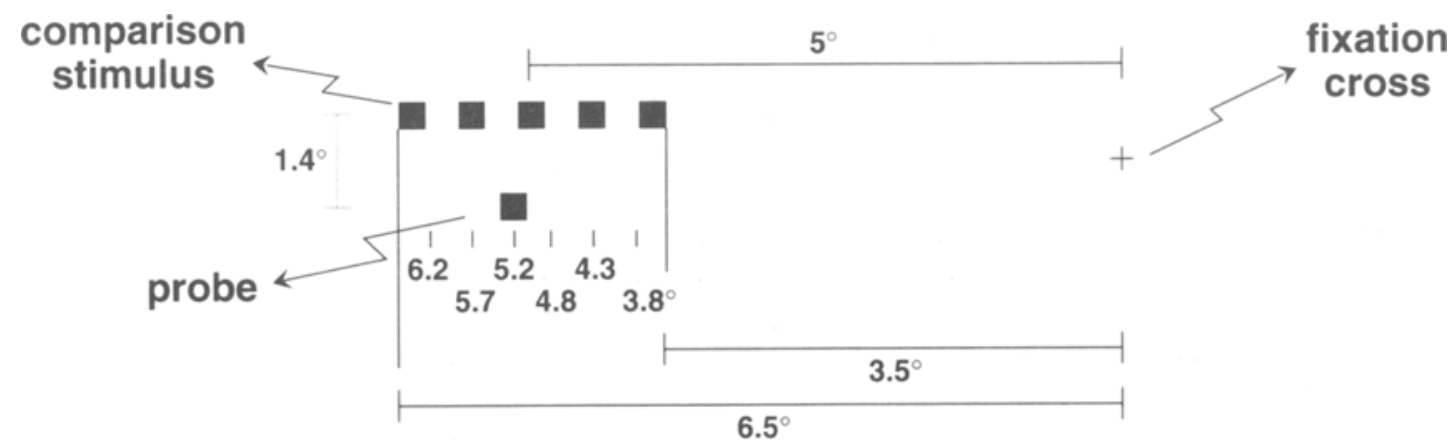

Figure 1. Stimulus presentation in the experiments. The participants fixated a cross in the middle of a screen. A stimulus configuration consisting of a single lower square (probe) and a spatially extended row of upper squares (comparison stimulus) appeared to the left or to the right of the fixation cross (here, $5^{\circ}$ to the left). The participants' task was to judge the position of the probe (presented at $3.8^{\circ}-6.2^{\circ}$ ), relative to the midposition of the comparison stimulus.

sible) spatial distortion within this map toward the fovea, and thus, any distortion should not affect the relation between the probe and the comparison stimulus. Therefore, the judgment of the position of the probe relative to the comparison stimulus should be more or less error free with simultaneous presentation. On the other hand, mislocalizations can be expected and have been found if the probe and the comparison stimulus are displayed successively as separate flashes (Hagenaar \& van der Heijden, 1997). Then, two configurations with different spatial information have to be superimposed, and relative mislocalizations between stimuli can occur. Thus, we expected to find relative mislocalizations of the probe only when it was not presented simultaneously with the comparison stimulus.

An additional variation comes from the following consideration. If the first stimulus establishes the spatial reference frame into which the second stimulus has to be integrated (or with which it has to be compared), the sequence of presentation could be important. For example, if the stimulus presented first is exposed to a different subjective displacement than is the second stimulus, errors in the relative judgments should be inverted with a change in the sequence of presentation. Therefore, in addition to the simultaneous presentation of the probe and the comparison stimulus, the participants were asked to judge the relative position of the probe when it preceded and when it followed the comparison stimulus.

\section{Method}

Apparatus and Stimuli. The experiments were carried out on a laboratory computer with a 14-in. screen (Rhothron rho-prof 200 ). The stimuli (dark squares on a light background) measured $0.33^{\circ} \times$ $0.33^{\circ}$ and were presented for one vertical retrace on the $71-\mathrm{Hz}$ monitor.' The display was positioned at a viewing distance of $50 \mathrm{~cm}$; its luminance was approximately $39 \mathrm{~cd} / \mathrm{m}^{2}$. The subject sat at a table with a chin and forehead rest and with the response keys set on a single box.
The stimulus display consisted of a horizontal upper row of five squares (the comparison stimulus), each separated by $0.33^{\circ}$, and a single lower square (the probe; see Figure 1). The positions of the upper five squares were held constant, with the central square being at $5^{\circ}$. The position of the probe had a vertical distance of $1.4^{\circ}$ to the comparison stimulus and was horizontally varied with respect to the midposition of the comparison stimulus by $\pm 0.2^{\circ}, 0.7^{\circ}$, and $1.2^{\circ}$; thus, the probe was presented at $3.8^{\circ}, 4.3^{\circ}, 4.8^{\circ}, 5.2^{\circ}, 5.7^{\circ}$, and $6.2^{\circ}$. The stimulus display appeared unpredictably toward the right or the left of the fixation point.

Design. The probe and the comparison stimuli were presented in either the left or the right hemifield. They appeared simultaneously, or the probe preceded or followed the comparison stimulus by an SOA of $\pm 112 \mathrm{msec}$. The probe was presented at the six positions $\left(3.8^{\circ}-6.2^{\circ}\right)$ around the objective $5^{\circ}$ midposition of the comparıson stimulus. Each combination of hemifield $\times$ SOA $\times$ probe position was presented to all the participants in a randomized sequence.

Procedure. Viewing was binocular in a dimly lit room. The participants initiated the stimulus presentations by simultaneously pressing two response keys. Each trial began with a beep and a centered fixation cross that remained visible until the response was given. The instructions stressed concentration on the fixation point. Three hundred milliseconds after the presentation of the fixation cross, the probe and the comparison stimulus were presented simultaneously or with an SOA of $\pm 112 \mathrm{msec}$. The participants were asked to identify the position of the lower square (probe) relative to the midposition of the upper squares (comparison stimulus) that is, whether it was perceived as being toward the left (indicated by pressing a left key) or the right (a right key). Following a response, the next trial was triggered after $1 \mathrm{sec}$, in a randomized sequence. A training period of 22 trials and the experimental session of 288 trials lasted about $30 \mathrm{~min}$.

Participants. Nine individuals, 22-36 years of age, were paid to participate in the experiment. All the participants reported having normal or corrected-to-normal vision.

\section{Results}

An inspection of the data reveals that the participants tended to judge the probe as being more to the left (as compared with the midposition of the comparison stimulus) when presented in the left hemifield; when presented in the right hemifield, the participants tended to 


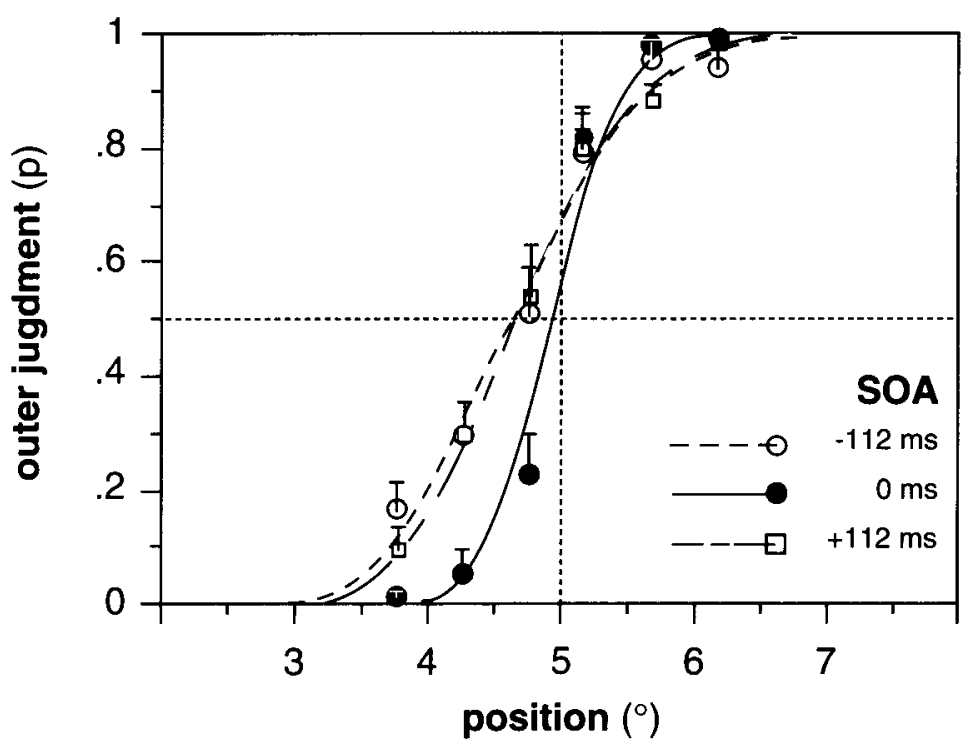

Figure 2. Mean probabilities (and standard errors between participants) for outer judgments of the probe (relative to the $5^{\circ}$ midposition of the comparison stimulus) as a function of its eccentricity. Curves are fitted functions of a probit analysis (Experiment $1, N=9$, every data point 144 observations; SOA, stimulus onset asynchrony).

judge the probe as being more to the right. Thus, the participants localized the probe as being more peripheral (outer judgments) than the comparison stimulus. Figure 2 presents the mean probabilities for peripheral, outer judgments of the probe as a function of its eccentricity. As can be seen, this tendency to outer judgments is only evident when stimuli are temporarily separated by an SOA.

For the statistical analysis, the $50 \%$ points of subjective equality (PSE) were computed by a probit analysis for every participant and condition (Finney, 1971; Lieberman, 1983). These PSE values were dependent variables in a 2 (left vs. right hemifield) $\times 3$ (SOAs of $-112,0$, and $+112 \mathrm{msec}$ ) analysis of variance (ANOVA). It revealed no effect of hemifield and no interaction (both $p s>.20$ ) but a significant effect of SOA $\left[F(2,16)=4.34, M S_{\mathrm{e}}=\right.$ $0.11, p=.031]$. The mean PSE value deviates from the objective midpositions by $-0.06^{\circ}$ for the 0 -msec SOA (with a mean standard error $[S E]$ between participants of $0.06),-0.36^{\circ}$ for the $-112-\mathrm{msec} \operatorname{SOA}(S E=0.08)$, and $-0.32^{\circ}$ for the $+112-\mathrm{msec}$ SOA $(S E=0.12)$. Negative deviations indicate PSE values lower than the objective midposition and, thus, a tendency to a greater number of outer judgments.

\section{Discussion}

The results are clear-cut. The first finding is that relative judgments are quite good when both stimuli are presented simultaneously. The second finding is that a mislocalization occurs when the probe is not presented simultaneously with the spatially extended comparison stimulus (cf. Hagenaar \& van der Heijden, 1997). Under these conditions, participants tend to localize the probe about $0.35^{\circ}$ more toward the periphery than is the midposition of the comparison stimulus. Note, of course, that these relative judgments do not justify any conclusions about absolute localizations of the stimuli. In particular, we cannot decide whether the probe is perceived as being more peripheral or the midposition of the comparison stimulus is perceived as being more foveal. Both possibilities could have led to the present relative judgments. We will answer this question in the context of one of the subsequent experiments.

The third finding is that the mislocalizations are not affected by whether the stimuli are presented with a positive or a negative SOA. Thus, if two successively presented spatial configurations have to be superimposed, it does not matter which stimulus comes first, the spatially extended comparison stimulus or the probe. This rules out simple temporal explanations. For example, it is possible to think of an interpretation of the mislocalization effect that is based on the idea that stimuli "move inward" over time. Then, when the probe is displayed, the previously presented comparison stimulus could already have "moved" foveally. However, if this were the case, the mislocalization should be reversed with the reversal of presentation, but it is not. This finding also rules out simple attentional accounts. Although the peripheral appearance of the first stimulus surely attracts processing, it could not be that this leads to a more accurate (or in- 
accurate) spatial perception of the second stimulus. Here, too, a reversal of the finding would be expected with a change in the order of presentation. Instead, this finding indicates that the localizations of stimuli are established rather independently of one another and that their different spatial extension is the critical point.

Before analyzing the effect in more detail in the subsequent experiments, it is worthwhile to note the findings of a simple control experiment. Remember, the main finding was that the participants tended to judge the probe as being more to the left when presented in the left hemifield, and vice versa; thus, our conclusion was that the participants localized the probe as being more toward the periphery than was the midposition of the comparison stimulus. However, one might argue that this effect only reflects a simple response tendencythat is, stimulation in the left hemifield recommends a left response (here, a left keypress); and stimulation in the right hemifield a right response (here, a right keypress). Although such a response tendency would not explain why the relative mislocalizations emerged only with an SOA between stimuli, we conducted a control experiment with different response devices. In this experiment, the perceived position of the probe was indicated by pointing to vertically arranged mouse fields with the words left/right (replacing the left/right keypress) or inner/outer. A disappearance of the mislocalization in the inner/outer condition, in which the participants indicate whether the probe is perceived as being more foveal (inner) or peripheral (outer) with respect to the midposition and which is thus independent of the hemifield of presentation, would point to a response tendency. None of the 8 participants' data in this control experiment showed this disappearance; rather, as in the present experiment, the mislocalizations emerged with a successive presentation of the probe and the comparison stimulus - and in both the left/right and the inner/outer conditions (Ertsey, 1997). Thus, an explanation of the effect by response tendency is not really defensible.

\section{EXPERIMENT 2}

The previous experiment showed that the simultaneous presentation of the two stimuli yields quite accurate relative spatial judgments, whereas a successive presentation reveals a tendency to mislocalizations. In this experiment, we will examine the temporal limits of this tendency - that is, we will display the probe and the comparison stimulus with various SOAs.

\section{Method}

Stimuli, Design, and Procedure. The stimuli, design, and procedure were the same as those in the previous experiment, with the following exception. Now, the probe followed the presentation of the comparison stimulus by SOAs of $0,42,98,210$, and $406 \mathrm{msec}$. These were presented with the six positions of the probe in a completely randomized sequence to all the participants.

Participants. Ten observers were paid for their participation.

\section{Results and Discussion}

When the probe and the comparison stimulus are presented simultaneously or in close succession (SOAs of 0 and $42 \mathrm{msec}$ ), mean PSE values quite accurately match the objective midposition of the comparison stimulus (Figure 3). With these SOAs, deviations from the midposition were only $-0.04^{\circ}(S E=0.06)$ and $-0.03^{\circ}$

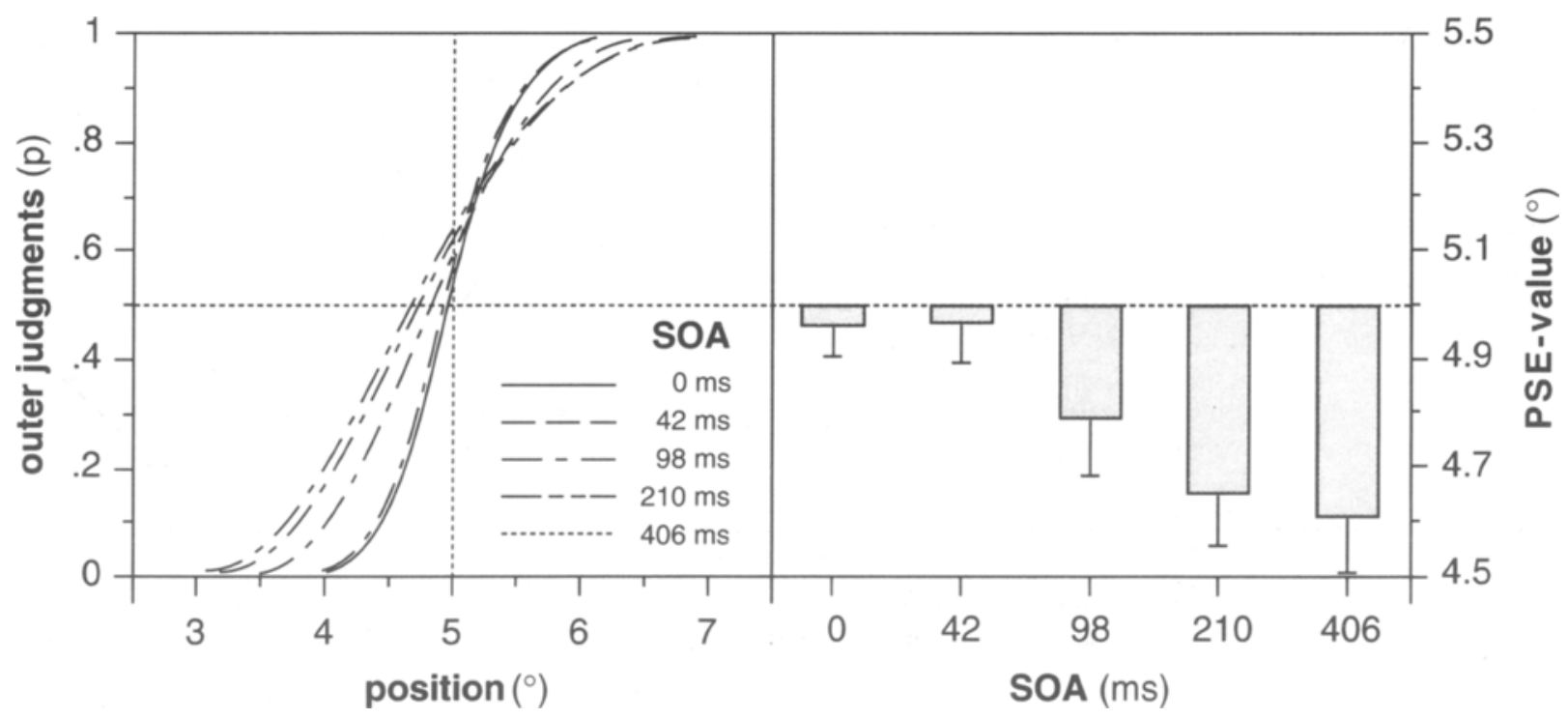

Figure 3. Fitted functions (left panel) and mean points of subjective equality (PSE) with standard errors between participants (right panel) for the five different stimulus onset asynchronies (SOAs) (Experiment 2, $N=10$ ). 
$(S E=0.07)$. The tendency to a greater number of outer judgments arises with the SOA of $98 \mathrm{msec}$, with a mean deviation of the PSE of $0.21^{\circ}(S E=0.11)$; it increases with the SOA of $210 \mathrm{msec}$ to $-0.35^{\circ}(S E=0.10)$ and remains nearly constant; for the SOA of $406 \mathrm{msec}$, the mean deviation equals $-0.39^{\circ}(S E=0.13)$. The one-way ANOVA reveals a significant effect of SOA $[F(4,36)=$ $\left.8.91, M S_{\mathrm{e}}=0.03, p<.001\right]$.

These results show that the relative mislocalizations of the probe emerge between the $42-$ and the $210-\mathrm{msec}$ SOA and that this tendency seems to remain constant with a further increase of the SOA. This result parallels the finding of Hagenaar and van der Heijden (1997), who presented stimuli with varying SOAs of $30-430 \mathrm{msec}$. In their study, mislocalization errors reached an asymptote at the $300-\mathrm{msec}$ SOA.

\section{EXPERIMENT 3}

Whereas, in the previous experiment, we examined the temporal limits between the probe and the comparison stimulus, in the present experiment, we checked whether the effect is influenced by varying eccentricities of presentation. Therefore, we displayed the probe and the comparison stimulus at either $3.5^{\circ}$ or $6.5^{\circ}$ eccentricity. These eccentricities match the inner and outer positions of the comparison stimulus in Experiment 1 (cf. Figure 1).

At least two outcomes were possible. If the foveally shifted mislocalization remained constant or increased with eccentricity but its size increased equally for the probe and the comparison stimulus, no effect of eccentricity would be expected. Then, the relative mislocalization emerges only from a rather constant difference in the displacement of the two stimuli. On the other hand, if the mislocalization increased differently for the probe and the comparison stimulus, eccentricity should affect the relative judgments. Such an outcome would be expected, for example, when both stimuli are shifted foveally but the comparison stimulus is foveally shifted by a higher percentage of eccentricity than is the probe.

\section{Method}

Stimuli, Design, and Procedure. The midposition of the comparison stimulus was presented at either $3.5^{\circ}$ or $6.5^{\circ}$ eccentricity. Correspondingly, the probe was presented at $2.3^{\circ}, 2.8^{\circ}, 3.3^{\circ}, 3.7^{\circ}$, $4.2^{\circ}$, or $4.7^{\circ}$ when the midposition of the comparison stimulus was displayed at $3.5^{\circ}$ and at $5.3^{\circ}, 5.8^{\circ}, 6.3^{\circ}, 6.7^{\circ}, 7.2^{\circ}$, or $7.7^{\circ}$ when the comparison stimulus was displayed at $6.5^{\circ}$. All combinations of comparison stimulus eccentricity and probe position were presented to all the participants in a completely randomized sequence. SOAs of 0 and $112 \mathrm{msec}$ were used. In every other regard, this experiment was identical to the previous experiments.

Participants. Ten individuals were paid to participate in the experiment.

\section{Results and Discussion}

When the probe and the comparison stimulus are presented simultaneously ( $\mathrm{SOA}$ of $0 \mathrm{msec}$ ), the mean PSE values quite accurately match the objective midpositions of the comparison stimuli. Deviations from the midposition were only $-0.06^{\circ}(S E=0.03)$ for the stimulus presentations at $3.5^{\circ}$ eccentricity and $-0.10^{\circ}(S E=0.05)$ at

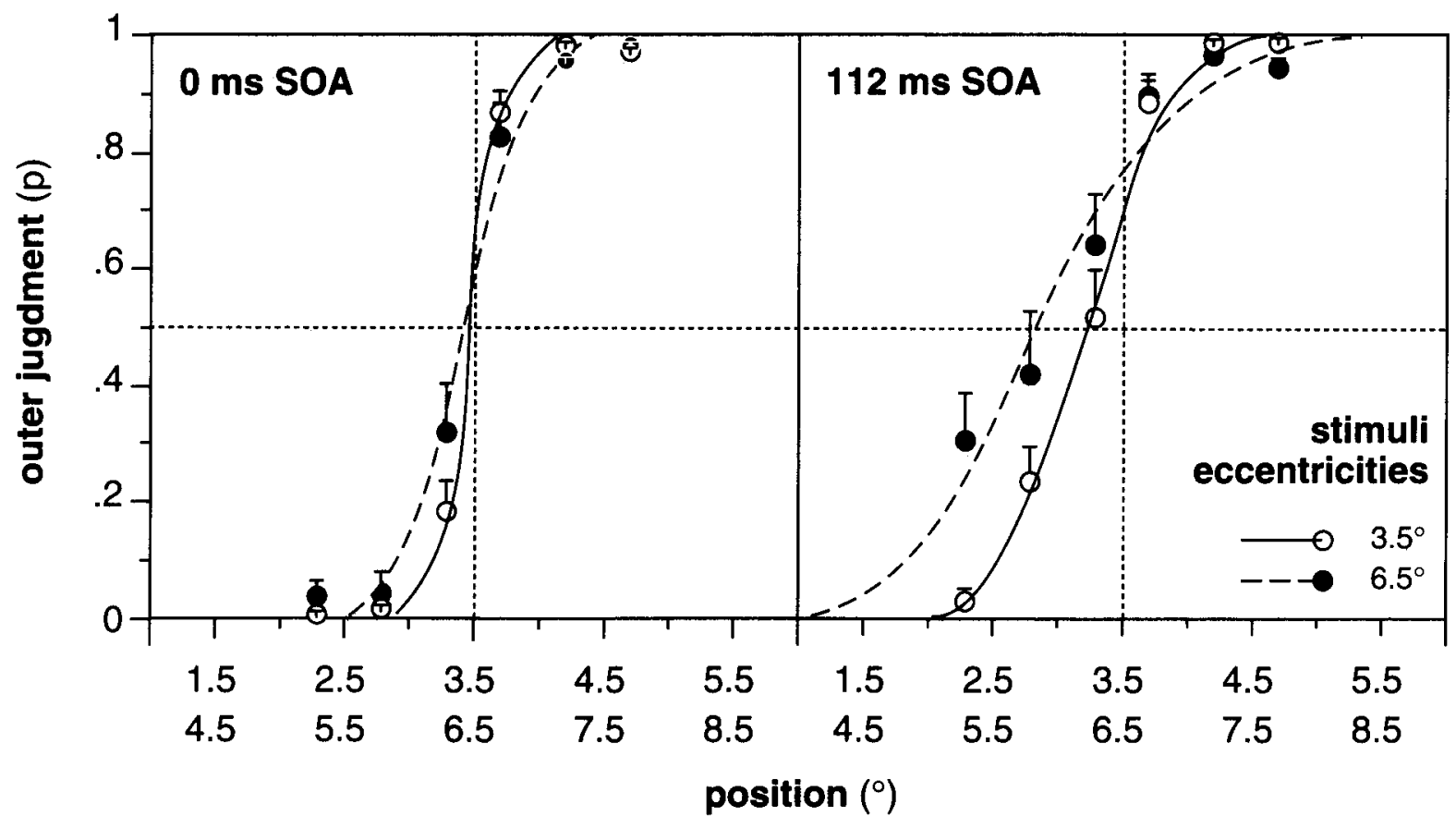

Figure 4. Mean probabilities for outer judgments and fitted functions at different eccentricities of presentation. The left panel depicts the stimulus onset asynchrony (SOA) of 0 msec, and the right panel the SOA of 112 msec (Experiment 3, $N=10$ ). 
$6.5^{\circ}$ eccentricity (Figure 4 , left panel). With the SOA of $112 \mathrm{msec}$, the deviations increased to $-0.34^{\circ}(S E=$ $0.10)$ and $-0.71^{\circ}(S E=0.22)$, respectively (Figure 4, right panel).

A $2 \times 2$ ANOVA yielded a significant effect of SOA $\left[F(1,9)=13.63, M S_{\mathrm{e}}=0.15, p=.005\right]$ and tendencies for eccentricity $\left[F(1,9)=5.07, M S_{\mathrm{e}}=0.08, p=.051\right]$, and the interaction $\left[F(1,9)=4.43, M S_{\mathrm{c}}=0.06, p=\right.$ .065]. An additional comparison among means confirmed the difference in the PSE values with the SOA of $112 \mathrm{msec}(t=2.27, p=.048$, two-tailed). In other words, an increasing eccentricity of presentation leads to an increase of the mislocalization. Since relative judgments are used, this result indicates that the foveal mislocalization increases differently for the probe and the comparison stimulus. Before we discuss this result in more detail, we will determine the foveal mislocalization of both stimuli separately.

\section{EXPERIMENT 4}

The relative judgments obtained in the previous experiments do not justify any conclusions about absolute localizations of the stimuli. In particular, we cannot really decide whether the probe is perceived as being more peripheral or the midposition of the comparison stimulus is perceived as being more foveal. In the present experiment, we examined these possibilities with an absolute judgment task, in which the participants were asked to adjust a cursor to the perceived midposition of the comparison stimulus or of the probe.

We expected a difference in absolute localizations owing to the different spatial extensions of the stimuli.
There was one indirect clue that spatially extended stimuli could be mislocated more toward the fovea than are the less extended stimuli. Rose and Halpern (1992) reported that foveal mislocalizations increased with a decreasing spatial frequency of vertically displayed bars. Since a low spatial frequency was confounded with a high spatial distance between bars, spatially extended stimuli should be more prone to foveal mislocalizations than are less extended stimuli. In other words, the comparison stimulus should be seen as being more foveal than the probe.

One problem with absolute localization tasks is that the cursor used to indicate the perceived location becomes part of the stimulus configuration. Thus, the adjusted position is probably not independent of the perceived spatial position of the cursor during the adjustment phase. To check this, we introduced different cursor starting positions.

\section{Method}

Stimuli and Procedure. An adjustment cursor was used to indicate the perceived position. It consisted of a vertical line of $0.65^{\circ}$ length that could be moved horizontally with a computer mouse. Its starting position was either the fixation cross or the $10^{\circ}$ position in the hemifield the stimulus was presented in. Throughout the experiment, lines were placed at the starting positions of the cursors that were identical in shape to the cursor and that should have avoided any additional abrupt onset on the screen after presentation. Thus, the cursor became visible only after presentation, when the participant had moved the mouse.

A trial began with a beep, and after $300 \mathrm{msec}$, the stimulus was displayed. Only the probe or only the comparison stimulus was presented in the left or the right hemifield at about $5^{\circ}$. The exact position of presentation varied between $5^{\circ} \pm 1.2^{\circ}$, to prevent the participants from always estimating the same position. After the stimulus

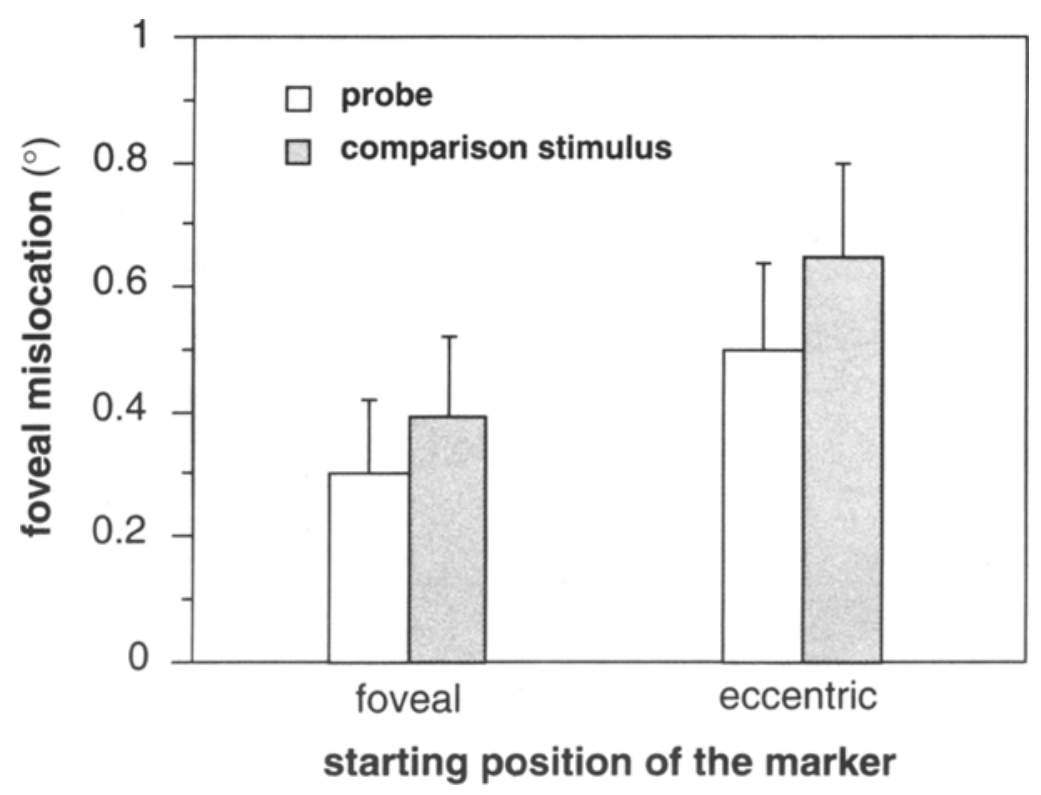

Figure 5. Mean foveal mislocalizations (and standard errors between participants) of the probe and the comparison stimulus for the two starting positions of the cursor (Experiment 4, $N=8$ ). 
presentation, the participants placed the cursor at the position at which they had perceived the center of the probe or the comparison stimulus. After having localized the perceived position, a mouse buttonpress confirmed the adjustment, and the cursor was moved to the fixation cross. The experimental procedure was self-pacedthat is, only after a further mouse click was the next trial initiated, after a 1-sec delay. The participants were also instructed to keep fixation during the cursor adjustment phase; however, fixation was not controlled. To familiarize the participants with the task, a training block was presented first.

Design. The probe or the comparıson stımuli were presented blockwise; their order of presentation was balanced between participants. In addition, the two starting positions of the cursor (at the fovea or at $10^{\circ}$ eccentricity) were varied, and 48 repetitions were obtained from each participant for each cell of the design.

Participants. Eight observers were paid to participate in the experiment.

\section{Results and Discussion}

Mean mislocalizations for each participant and condition were entered in a 2 (probe vs. comparison stimulus) $\times 2$ (cursor starting positions) ANOVA. It revealed greater foveal mislocalizations for the midposition of the spatially extended comparison stimulus, as compared with the less extended probe. Their mean adjusted deviations toward the fovea were $0.52^{\circ}$ and $0.40^{\circ}$, respectively $[F(1,7)$ $=18.43, M S_{\mathrm{e}}=0.01, p=.004$; see Figure 5].

In addition, the cursor starting positions affected the mislocalizations, $\left[F(1,7)=18.75, M S_{\mathrm{e}}=0.02, p=\right.$ $.003]$. When starting at the eccentric positions, the cursor was adjusted more foveally than when starting at the fixation cross. There was no indication of an interaction of both factors.

A comparable influence with regard to the cursor starting positions has been reported by van der Heijden et al. (1999). Both studies, therefore, indicate that the cursor and its starting position contribute to and affect the whole perceived spatial arrangement. To understand this, it could be worthwhile, in each experimental trial, to distinguish between a stimulus perception part and a cursor perception part. In the stimulus perception part, the participants assess the midposition of the spatially extended comparison stimulus or of the less extended probe. In the cursor perception part, the participants try to reproduce this assessed position with the cursor. Since it is known that it is difficult not to follow a cursor with the eyes (see, e.g., Findlay, 1987), this part of the task is probably accompanied by eye movements or, at least, by a tendency to move the eyes. If the cursor starts at the foveal fixation cross, the direction of cursor movements and of eye movements (or their tendencies) agree - that is, their common reference point is the fixation cross. If the cursor starts at the peripheral position, an additional reference point comes into play--that is, the peripheral starting position of the cursor. It is not surprising that this divergence in the procedure affects the adjustments (for an estimation of the individual variance components of both starting positions, see van der Heijden et al., 1999).
We can conclude that the adjustment task used in the present experiment yields only approximate indications of the absolute mislocalizations that are due to the cursor perception part. The fact that we only obtained approximations might be responsible for the discrepancy that becomes apparent when we calculate quantitatively the relative mislocalizations from the absolute localizations. Whereas, in the present experiment, the foveal mislocalization is only about $0.12^{\circ}$ larger with the comparison stimulus than with the probe, the PSE values between both stimuli indicated a difference of about $0.35^{\circ}$ in Experiment 1.

Another source of this discrepancy might be the dissociations that are often observed between perceptual and motor tasks. Some visual illusions are deceptive in the perceptual judgment of size but only marginally influence the size estimations used in pointing. For example, although the Müller-Lyer figure indicates size differences in line judgments, observers are quite accurate in an open-loop task in pointing to the lines' end positions (Mack, Heuer, Villardi, \& Chambers, 1985; Post \& Welch, 1996). It seems reasonable that the mechanisms responsible for these kinds of dissociations affect also the quantitative comparison between the present relative judgments and the cursor adjustments.

The fact that we only obtained approximate values, however, does not diminish the importance of the qualitative findings. Our results clearly show that the comparison stimulus is perceived as being more foveal than the probe. This leaves us with no other viable interpretation than that the mislocalizations in the relative judgment task emerge from comparable foveal displacements. In the final three experiments, we examined, with the relative judgment task, what could account for the larger foveal displacements of the spatially extended stimulus.

\section{EXPERIMENT 5}

What accounts for the larger foveal displacements of the spatially extended comparison stimulus? Answering this question requires some knowledge of the factors that affect the size of foveal mislocalizations. Therefore, in the present experiment, we varied the spatial extension of the comparison stimulus - that is, we compared relative judgments made with a spatially less extended comparison stimulus and those made with a spatially more extended one. Three outcomes were possible. First, given the effect of eccentricity (Experiment 3 ) and assuming that the amount of foveal mislocalization is mainly affected by the outer position, the displacement should be more pronounced with the spatially more extended comparison stimulus. Second, if the visual system forms a compromise between the inner and the outer position of the comparison stimulus, its spatial extension should be less critical for the relative judgments, and only minor effects should be expected. Third, if we assume that it is the inner position that affects the foveal 
displacement, the mislocalization should be less pronounced with the spatially more extended comparison stimulus. It is obvious that only the first possibility is in accordance with the appearance of the phenomenon.

We can examine whether there is an influence of the comparison stimulus per se with a comparison stimulus of the same spatial extension as the probe. Since it is possible that the comparison stimulus produced a mislocalization by its mere presentation (and not by its spatial extension), a comparison stimulus that was identical to the probe was added. According to our assumptions, this comparison stimulus should not evoke the tendency to a greater number of outer judgments of the probe.

\section{Method}

Stimuli. The stımulus presentation was essentially the same as that in Experiment 1, except that the comparison stimulus now consists of one, three, or seven squares. These stimuli were constructed simply by adding (or removing) squares to (from) the left and the right of the original five-square comparison stimulus (Figure 1). The spatial extension was now $0.33^{\circ}$ for the one-square comparison stimulus, $1.68^{\circ}$ for the three-square comparison stimulus, and $4.27^{\circ}$ for the seven-square comparison stımulus. Their objective midpositions remained unchanged at $5^{\circ}$ eccentricity.

Design and Procedure. The probe and the three different comparison stimuli (one, three, or seven squares) were presented with SOAs of 0 and $112 \mathrm{msec}$. The presentation of the comparison stimuli was varied blockwise, with the order of conditions balanced between participants. In all other aspects, the design and procedure was the same as those in Experiment 1. Including instructions, this experiment lasted $45 \mathrm{~min}$.
Participants. Fourteen individuals were paid to participate in the experiment.

\section{Results}

The left panel of Figure 6 presents the probabilities of outer judgments as a function of eccentricity with a simultaneous presentation of the probe and the comparison stimulus ( $\mathrm{SOA}=0 \mathrm{msec}$ ). As was expected, the PSE values nearly match the objective midposition. A mean deviation of $+0.02^{\circ}(S E=0.02$ ) was observed for the one-square comparison stimulus, of $-0.03^{\circ}(S E=0.03)$ for the three-square comparison stimulus, and of $-0.04^{\circ}$ $(S E=0.06)$ for the seven-square comparison stimulus.

As in the previous experiments, the participants tended toward outer judgments with the spatially extended three- and seven-square comparison stimuli when presented with an SOA (right panel of Figure 6). The mean PSE values deviated from the midposition by $-0.20^{\circ}$ $(S E=0.13$ ) for the three-square comparison stimulus and by $-0.35^{\circ}(S E=0.12)$ for the seven-square comparison stimulus. A comparison among means, which examined the three- against the seven-square condition with nonsimultaneous presentation, was significant $(t=$ $3.33, p=.005$, two-tailed).

A reversed effect is observed with the one-square comparison stimulus. Here, the mean PSE value deviates from the midposition by $+0.43^{\circ}(S E=0.12)$; thus, there is a tendency to more inner judgments with this condition. A two-way ANOVA of the PSE values revealed a

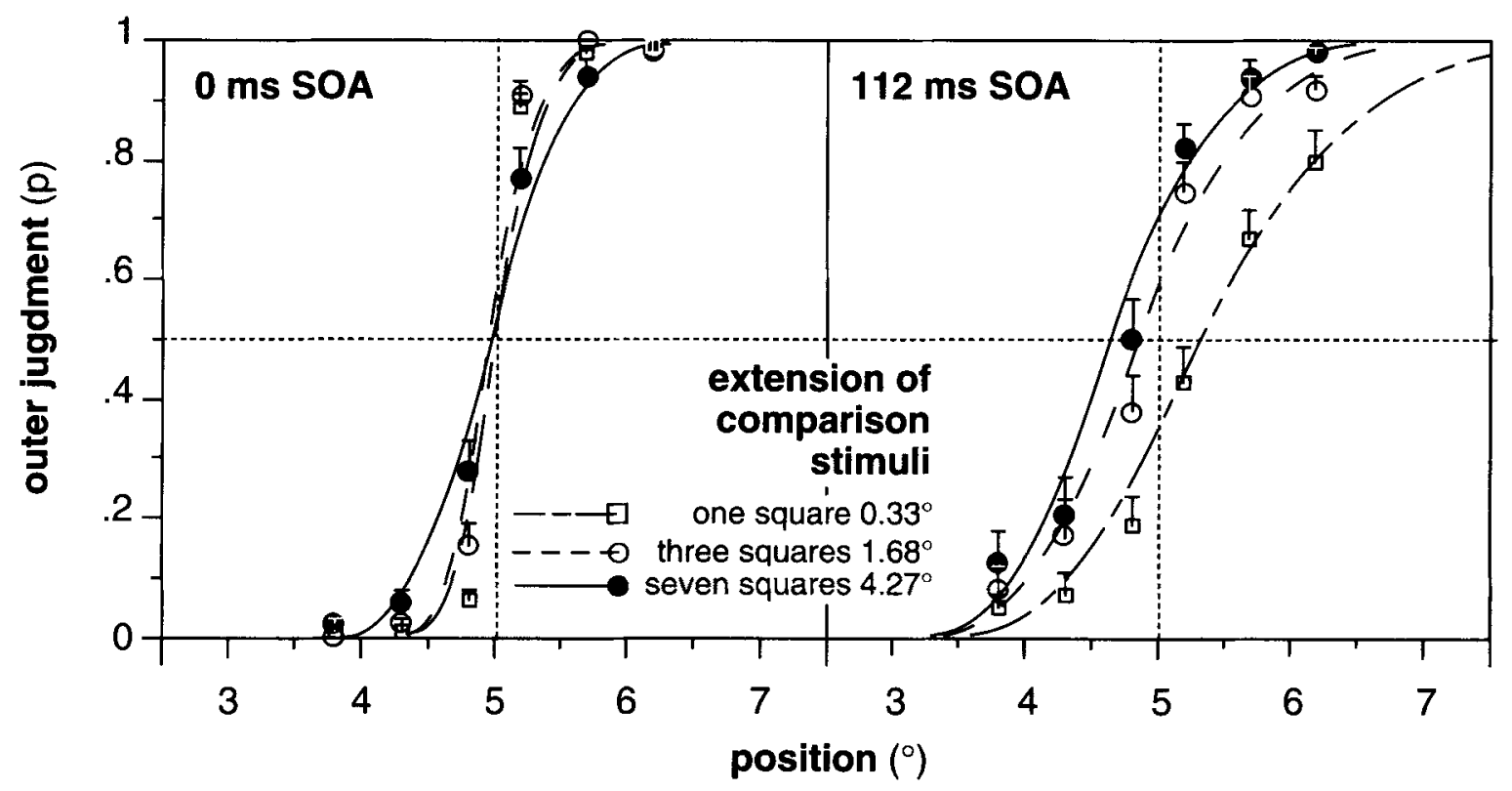

Figure 6. Mean probahilities for outer judgments and fitted functions for different extensions of the comparison stimulus. The left panel depicts the stimulus onset asynchrony (SOA) of $0 \mathrm{msec}$, and the right panel the SOA of $112 \mathrm{msec}$ (Experiment 5 , $N=14$ ). 
significant effect of extension of the comparison stimuli $\left[F(2,26)=25.46, M S_{\mathrm{e}}=0.05, p<.001\right]$ and a significant interaction with SOA $\left[F(2,26)=28.97, M S_{\mathrm{e}}=\right.$ $0.04, p<.001]$.

\section{Discussion}

The difference between the three- and the sevensquare conditions meets the expectation that the amount of foveal mislocalization is mainly affected by the outer positions of the comparison stimulus. In that case, the mislocalization should be more pronounced with the spatially more extended comparison stimulus, and that is what the data represent. Thus, the present data show that the amount of eccentricity covered by the comparison stimulus leads to an increase of the mislocalization.

To the contrary, the condition with the one-square comparison stimulus reveals a somewhat unexpected finding. On the basis of our assumptions, a comparison stimulus of the same spatial extension as the probe would produce no mislocalization; but the effect was not only canceled, it was even reversed. The tendency to make a greater number of outer judgments was turned around to a tendency to make a greater number of inner judgments. What can account for this reversal?

The greater number of inner judgments with the onesquare comparison stimulus can be understood simply, when we add the assumption that the localization judgment of the probe becomes more variable in accordance with the probe's eccentricity, which varied between $3.8^{\circ}$ and $6.8^{\circ}$, whereas the one-square comparison stimulus was fixed at $5^{\circ}$. In other words, the distributions of perceived probe positions are assumed to get flatter the fur- ther this stimulus is from the fixation point- - that is, the localization distributions are steep at $3.8^{\circ}$ and get flatter toward $6.8^{\circ}$ eccentricity. From that, it simply follows that the overall distribution has a skewness toward inner judgments. In absolute terms, this would result in a greater number of inner than outer judgments and, thus, could produce a reversed effect. It is beyond the scope of the present paper to elaborate on this idea. At least, more empirical data are needed to clarify this reversal completely.

In any case, it can be concluded that the mere presentation of a comparison stimulus does not produce the tendency toward outer mislocalizations that is observed with the spatially extended comparison stimulus. On the contrary, this result indicates that these mislocalizations are more underestimated than overestimated.

\section{EXPERIMENT 6}

The previous experiment showed that a spatially more extended comparison stimulus increases relative mislocalization, as compared with a less extended comparison stimulus. In this experiment, we examined another variation in the configuration of that stimulus. So far, the comparison stimulus has consisted of a row of five squares. However, our theoretical considerations do not take into account this spatial chaining of stimuli but are based only on the spatial extension of the comparison stimulus. In order to check whether the effect is produced only by the spatial chaining of squares within the comparison stimulus, we compared relative judgments of the present five-square stimulus with those of a single rectangle of identical spatial extension.

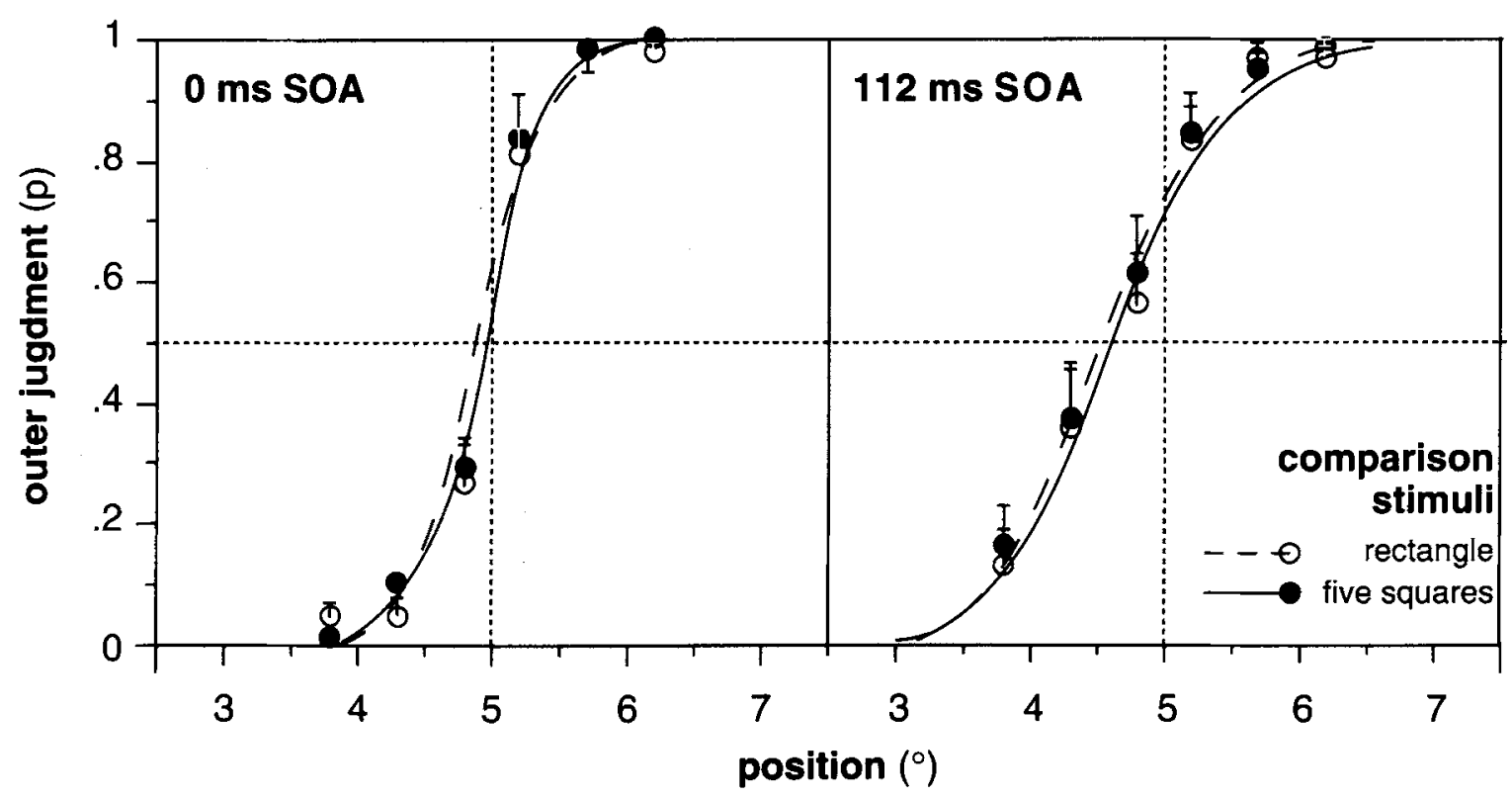

Figure 7. Mean probabilities for outer judgments and fitted functions for both comparison stimuli. The left panel depicts the stimulus onset asynchrony (SOA) of $0 \mathrm{msec}$, and the right panel the SOA of $112 \mathrm{msec}$ (Experiment 6, $N=12$ ). 


\section{Method}

Stimuli, Design, and Procedure. The stimuli, design, and procedure were basically the same as those in Experiment 1 (cf. Figure 1), but now the five-square comparison stimulus was contrasted with a comparison stimulus that consisted of a single rectangle with the same spatial extension $\left(3^{\circ} \times 0.33^{\circ}\right)$. Under both conditions, the participants were asked to identify the position of the probe relative to the midposition of the comparison stimulus. All stimulus combinations - that is, the two comparison stimuli, the six positions of the probe, and the two SOAs of 0 and $+112 \mathrm{msec}$ - were presented in a completely randomized sequence.

Participants. Twelve observers were paid to participate.

\section{Results and Discussion}

The left panel of Figure 7 presents the probabilities of outer judgments as a function of eccentricity for the 0 -msec SOA. Here, both fitted curves for the different comparison stimuli (five squares vs. single rectangle) show only a slight tendency to make a greater number of outer judgments with the single rectangle as comparison stimulus, but both PSE values nearly match the objective midposition (mean deviations of $-0.09^{\circ}, S E=0.06$, and of $-0.13^{\circ}, S E=0.07$, respectively).

As can be seen in the right panel of Figure 7, the tendency to make outer judgments clearly occurred with the 112-msec SOA, irrespective of condition-that is, with the five squares as well as with the single rectangle as the comparison stimulus. Their mean PSE values deviated from the midposition by $-0.45^{\circ}(S E=0.14)$ and by $-0.52^{\circ}(S E=0.16)$, respectively. A two-way ANOVA of the PSE values revealed a significant effect of SOA $\left[F(1,11)=11.32, M S_{\mathrm{e}}=0.15, p=.006\right]$, a tendency between the comparison stimulus conditions $[F(1,11)=$ $\left.4.52, M S_{\mathrm{e}}=0.01, p=.057\right]$, and no indication of an interaction $(F<1)$. The statistical tendency to a slight increase of outer judgments in the single-rectangle condition could have something to do with a more general mislocalization of the midposition in that stimulus. The finding that the tendency occurred with the $0-\mathrm{msec}$ as well as with the 112-msec SOA points to another mechanism. In sum, the mislocalization effect is not diminished when the five-square comparison stimulus is replaced by a single rectangle. Thus, it is not the spatial chaining of the five squares that produces the effect.

\section{EXPERIMENT 7}

As was mentioned in the introduction, we began with the idea that the near- and/or the far-fovea edge of a spatially extended stimulus contributes to the foveal mislocalization of the whole stimulus. If that is correct, it should be possible to manipulate differently the salience of the edges, in order to emphasize their relevance for the localization of the stimulus. This is especially plausible when we consider that salient aspects in a stimulus configuration can attract stimulus processing and influence its localization (the so-called "pop-out" effects; see, e.g., Saarinen, 1996).

In most of the experiments reported so far (with the exception of Experiment 5), the comparison stimulus consisted of five squares identical in intensity and size. Now, we changed it to one dark square and four white squares. The dark square was assumed to be the more salient square, owing to its higher contrast (see, e.g., Treisman \& Gormican, 1988). We placed it at either the inner or the outer edge of the comparison stimulus. From previous re-

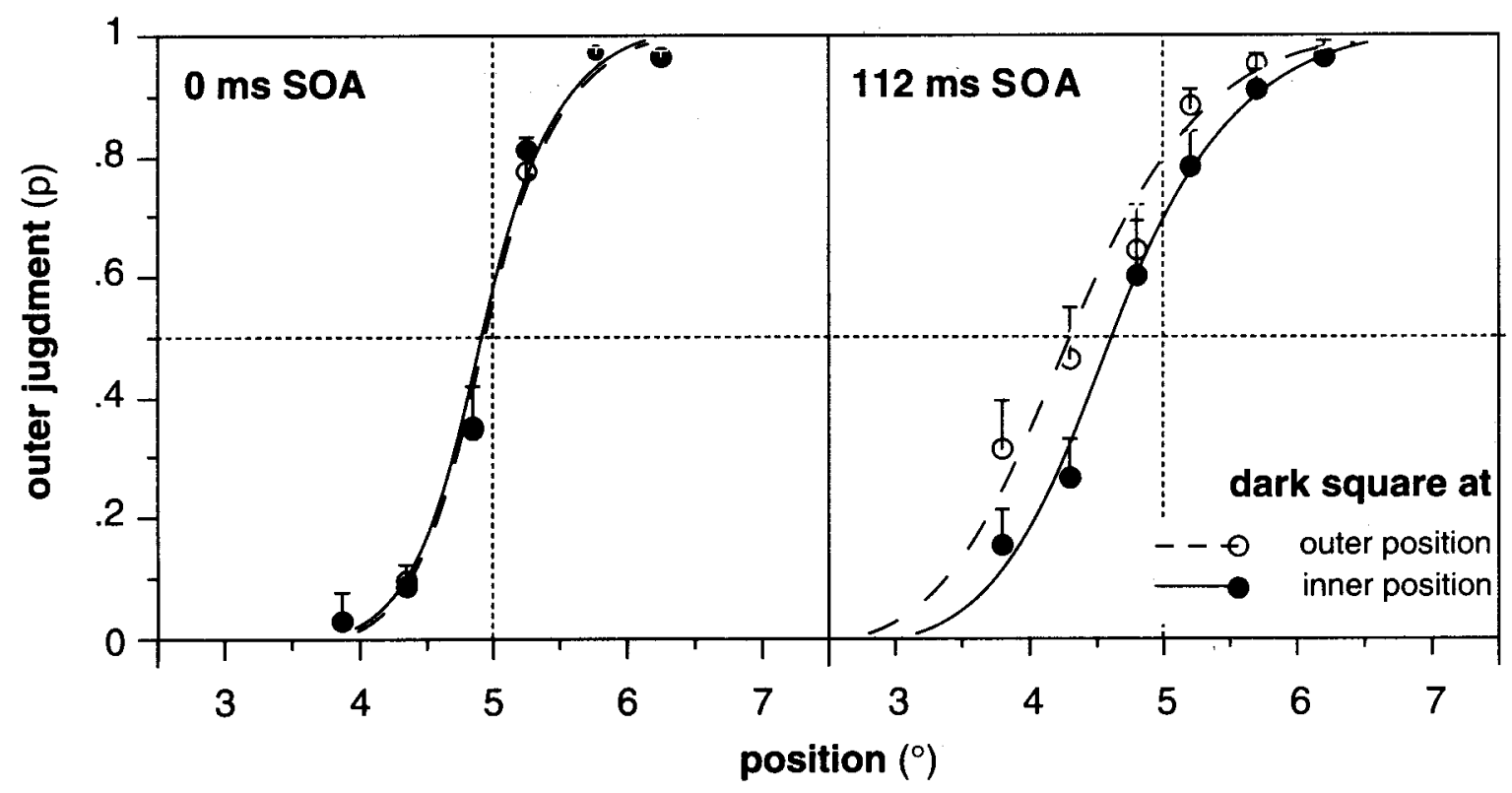

Figure 8. Mean probabilities for outer judgments and fitted functions for both positions of the dark square. The left panel depicts the stimulus onset asynchrony (SOA) of 0 msec, and the right panel the SOA of $112 \mathrm{msec}($ Experiment $7, N=10)$. 
search, we know that mislocalization increases with eccentricity (Experiment 3; cf. also van der Heijden et al., 1999); so, if the position of the salient square determines the foveal displacement of the comparison stimulus, relative mislocalization should be higher when it is in the outer position than when it is in the inner position.

\section{Method}

Stimuli, Design, and Procedure. The stimulı, design, and procedure were basically the same as those in Experiment 1, but now the five squares of the comparison stimulus consisted of four outlined white squares and one dark square. The dark square was placed at either the inner or the outer edge of the comparison stimulus. Remember that stimuli were presented black-on-white and that, therefore, the dark square was the salient feature in the configuration. To emphasize its exceptional position, in this experiment, the probe was now also an outlined square. Both conditions, the dark square at the inner or the outer edge, were presented with the six positions of the probe and the two SOAs of 0 and $+112 \mathrm{msec}$ in a completely randomized sequence. As in the previous experlments, the participants were to judge the probe relative to the midposition of the comparison stimulus- that is, of the five squares composed of one dark and four outlined squares.

Participants. Ten observers were pald to participate.

\section{Results and Discussion}

The left panel of Figure 8 presents the probabilities of outer judgments as a function of eccentricity for the 0 -msec SOA. Here, both fitted curves for the different comparison stimuli (dark square at the outer vs. the inner position) match perfectly, and the PSE values nearly match the objective midposition (mean deviations of $-0.12^{\circ}, S E=0.07$, and of $-0.14^{\circ}, S E=0.05$, respectively). In the present context, this finding is important to note, since it indicates no general difference in the perceptibility of the midpositions of the different comparison stimuli.

However, as can be seen in the right panel of Figure 8, the tendency to make outer judgments is increased when the dark square is presented at the outer edges of the comparison stimulus, as compared with the inner edges. Their mean PSE values deviate from the midposition by $-0.79^{\circ}(S E=0.19)$ and by $-0.38^{\circ}(S E=0.14)$, respectively. A two-way ANOVA of the PSE values revealed a significant effect of SOA $\left[F(1,9)=14.11, M S_{\mathrm{e}}=0.14\right.$, $p=.005]$, a tendency between the inner and outer positions of the dark square $\left[F(1,9)=4.86, M S_{\mathrm{e}}=0.08, p=\right.$ $.055]$, and a significant effect of the interaction $[F(1,9)=$ 15.49, $\left.M S_{\mathrm{e}}=0.03, p=.003\right]$. A comparison among means confirmed the expected difference in the PSE values with the SOA of $112 \mathrm{msec},(t=2.92, p=.008$, onetailed).

Thus, the configuration of the comparison stimulus can affect the relative judgments. Our interpretation is that the salient dark square attracts processing and that, therefore, the inner or the outer edge affects the foveal displacement of the whole comparison stimulus. As this should be increased with the dark square at the outer edge, the relative judgments should correspondingly reveal a difference, just as the results have shown.

However, one might have doubts about the presumed salience of the dark square. It is possible to argue, for example, that the dark square was simply "ignored" and that the participants based their responses on the white squares only. The midposition of the white squares was more inner with the black square at the outer position, and vice versa. So, although this view does not take into account the salience of the dark square, the findings would come as no surprise. With this explanation, however, it remains unclear why this "ignoring" of the dark square was not applied when the probe and the comparison stimulus were presented simultaneously $(0-\mathrm{msec}$ SOA). In this simultaneous condition, the participants were quite good at adjusting the midposition of the comparison stimulus, and no differences between the inner and the outer conditions were observed. Thus, "ignoring" of the dark square is unlikely.

\section{GENERAL DISCUSSION}

The present study was concerned with a phenomenon that consists of a peripheral mislocalization observed with briefly presented stimuli of different spatial extensions. Asked to judge the parafoveal position of a probe with respect to the midposition of a spatially extended comparison stimulus, participants tended to localize the probe as being more toward the periphery than the midposition of the comparison stimulus. However, describing the mislocalization's direction in this way is misleading, although it was formulated with respect to the participants' task. Experiment 4 revealed, with an absolute judgment task, that the comparison stimulus is localized more foveally than the probe, which has the same consequence with regard to the relative judgments but makes it more likely that it is the comparison stimulus that mainly contributes to the error.

Still, the size of relative mislocalization is huge, as compared with the well-accepted high spatial acuity of the visual system. In the present experiments, in which stimuli were presented at $5^{\circ}$ eccentricity, the PSE values of the probe deviated up to $0.8^{\circ}$ from the objective midposition of the comparison stimulus. The exact deviations varied with the experimental condition. The mislocalization emerged only when the probe and the comparison stimulus were presented in succession, independently of whether the less extended probe or the spatıally extended comparison stimulus came first (Experiment 1). The size of the mislocalization was dependent on the SOA between the presentations--that is, mislocalizations emerged between a 42- and a 98 -msec SOA and reached an asymptotic level beyond a $200-\mathrm{msec}$ SOA (Experiment 2 ). In addition, the amount of the mislocalization depended on the eccentricity of presentation, so that with increasing eccentricity, the mislocalization increased, too (Ex- 
periment 3). The last two experiments checked basic changes in the configuration of the comparison stimulus: The mislocalization increased when a more extended (seven-square) comparison stimulus was presented instead of a less extended one (three-square, Experiment 5). It slightly increased when a single rectangle was used as the comparison stimulus, indicating that it was not the spatial chaining of squares but the spatial extension of the whole comparison stimulus that produced the effect (Experiment 6). The mislocalization was clearly modified when the structure within the comparison stimulus was varied - that is, when a salient dark square was placed at its outer or its inner position (Experiment 7).

After this brief summary of our main results and before trying to provide an explanation, it is worthwhile to point out that our pattern of results is not simply another interesting but isolated pattern of results. The relevant point here is that our findings corroborate and consummate the outcome obtained by Hagenaar and van der Heijden (1997) in a classic visual information selection task - the partial-report bar-probe task introduced by Averbach and Coriell (1961). In the version of the task used by Hagenaar and van der Heijden (1997), a linear horizontal row of seven letters or digits was displayed. The row was centered on the fixation point. Only one of the letters or digits per trial had to be reported. This item was indicated with a small arrow just above one of the positions in the array. The arrow could appear in various temporal positions, relative to the moment of presentation of the seven-item array. One major finding reported by Hagenaar and van der Heijden (1997) was that, especially with nonsimultaneous presentations of the array and the arrow, most errors were central-near-location errors - that is, they consisted of the names of items that were in the array but adjacent to and at the foveal side of the letter indicated by the arrow. This result is consistent with and can be explained by the results of our Experiment 4 . When extrapolated to smaller distances, Experiment 4 shows that an object presented at a nonfoveal position is perceived as being closer to the fovea than it actually is. The item array in Hagenaar and van der Heijden's (1987) experiment was located centrally, so no inward movement of that array was possible. With target positions 1,2, and 3, however, the arrow was presented left of fixation, and with target positions 5,6 , and 7 , it was presented to the right. So, with these target positions, a foveal displacement of the arrow was to be expected (see van der Heijden et al., 1999, for further evidence). This foveal displacement of the arrow, together with the fixed, correct position of the array, immediately explains the abundance of the central-near-location errors: Participants simply tried to answer with the name of the item that, according to their perception, was indicated by the (centrally displaced) arrow.

Another major finding reported by Hagenaar and van der Heijden (1997) was that the number of (central-near) location errors increased with increasing SOAs, reaching an asymptote with an SOA of about $200-300 \mathrm{msec}$ (for related observations, see, also, Hagenaar \& van der Heijden, 1995; Mewhort, Campbell, Marchetti, \& Campbell, 1981 ). Interestingly, the same range of SOAs was found to be of relevance in the present study. Experiment 2 shows that the relative mislocalizations emerge between 42 and $210 \mathrm{msec}$ and remain approximately constant with a further increase of SOA.

A third important, new, and rather unexpected finding reported by Hagenaar and van der Heijden (1997) was that an abundance of central-near-location errors was not only found when the arrow followed the array (i.e., with positive SOAs) but also when the arrow preceded it (i.e., with negative SOAs). This finding is clearly paralleled by the results of our Experiment 1, which show almost identical relative displacements with SOAs of +112 and $-112 \mathrm{msec}$. This coincidence-similar numbers of (central-near) location errors in the partial-report bar-probe task and similar (relative) displacements in our position judgment task with positive and negative SOAs - strongly supports the point of view, presented above, that the phenomenon our research was concerned with reflects the same underlying factor as the one that was at the basis of the main pattern of results in Hagenaar and van der Heijden's (1997) partialreport bar-probe tasks (see, also, van der Heijden et al., 1999).

The present pattern of results allows us to evaluate possible explanations of the relative mislocalization effect and to launch a general explanation for the foveal displacement effect. To show this, we first have to prove that the relative mislocalization and the foveal displacement are indeed two sides of the same coin. Then we will discuss a possible interpretation of the foveal mislocalization.

To show that the relative mislocalization observed in one task arises from the general tendency to localize briefly presented stimuli more foveally than they actually are, we first have to evaluate possible explanations that do not refer to this tendency. Such an explanation can, for example, be based on the assumption that the perceived midposition of an extended stimulus deviates from its objective midposition (the perceptual-center, or $P$-center, hypothesis). These P-center deviations were found to exist for temporally extended acoustic stimuli, as well as for spatially extended visual stimuli (e.g., Scott, 1998; Vos, Bocheva, Yakimoff, \& Helsper, 1993). At least in vision research, the term $P$-center is sometimes used synonymously with the term center of gravity (COG; see, e.g., Vos et al., 1993). In the present paper, we will refer to the term P-center only as the perceived midposition of a stimulus, whereas the term COG will be used to mark the position to which the eye is attracted, irrespective of what is perceived to be the midposition of that stimulus. We will first focus on the P-center assumption and come back to the COG concept later on. At first sight, the P-center assumption can explain the present relative mislocalization in a simple way. If the perceived midposition of our spatially extended comparison stimulus is located more foveally and if the 
probe is compared with this $\mathrm{P}$-center, a relative mislocalization will occur. With this explanation, then, there is no need to refer to different foveal displacements of the probe and the comparison stimulus. The relative displacement simply arises from the spatial relation between the P-center of the comparison stimulus and the probe.

However, there are several aspects of our results that make us doubt this idea. First, with this explanation, it remains unclear why there is no systematic error in the conditions in which the probe and the comparison stimulus are presented simultaneously. Under this condition, the mislocalization should still exist when participants do not change their localization strategy - that is, comparing the position of the probe with the P-center. As the mislocalization does not emerge with simultaneous presentation, it remains to be explained why participants change their strategy in dependence on the SOA. Second, it is very likely that the P-center varies with the configuration of the comparison stimulus. Thus, if in Experiment 7 , the salient dark square is presented at the outer position, it can be assumed that the P-center is shifted toward it. But then, if the probe localization arises from the comparison with the P-center, the findings should be reversed: A more outer P-center should produce a greater number of inner judgments and vice versa. Third, and most important, the relative judgments of Experiment 3 and the absolute judgments of Experiment 4 clearly indicate that the comparison stimulus and the probe are located separately and with another foveal error, even if presented alone. So, we can conclude that the relative displacement of the comparison stimulus and the probe emerges from a misperception of their absolute spatial coordinates.

On the other hand, deviations from the objective midposition are observed only with successive presentation of the stimuli, whereas a simultaneous presentation reveals no systematic error. We argued that when the probe and the comparison stimulus are flashed simultaneously, they are processed in one spatial map as a single stimulus. Then, a (possible) spatial distortion within this map is subject to all stimulus aspects and, thus, should not affect the relative judgment between the probe and the comparison stimulus. This is what has been shown. However, mislocalizations were expected and were found, if the probe and the comparison stimulus were displayed successively as separate flashes. In this case, two configurations with different spatial information have to be superimposed, and relative mislocalizations between the stimuli could occur.

This consideration touches upon the question of whether the spatial error in relative localization is produced only by the temporal succession in the presentation. It is possible to imagine that stimuli simply "move inward" over time. Then, when the probe is displayed, the previously presented comparison stimulus could have already "moved" foveally. We reject this view for two reasons. First, the difference in the absolute judg- ment task of Experiment 4 shows an increased foveal displacement with the spatially extended comparison stimulus, as compared with the probe. Here, temporal properties of presentation are identical for both the stimuli. And second, there is absolutely no effect of whether the comparison stimulus precedes or follows the probe (Experiment 1). Such an effect is, however, to be expected if the effect has its origin only in the temporal properties of presentation. So, we can further conclude that it is really the different spatial extensions of the stimuli and their different foveal displacements that produce the effect.

The different foveal displacements are assumed to originate from the more outer eccentricity of the comparison stimulus. In fact, Experiment 5 shows that the amount of foveal mislocalization is affected by this eccentricity. When varying the spatial extension of the comparison stimulus, the mislocalizations are more pronounced with the spatially more extended - and, thus, more eccentric-comparison stimulus. This finding corroborates and consummates the outcome obtained in Experiment 3, which revealed a general increase of the effect with more eccentric presentations.

What still remains to be explained is the general tendency to localize briefly presented stimuli more foveally than they actually are and the fact that this tendency increases with the eccentricity of the stimuli. Experiment 4 shows that the tendency to localize briefly presented stimuli more foveally covers about $10.4 \%$ of eccentricity for the spatially extended comparison stimulus and $8 \%$ for the probe. Comparable findings have been reported earlier (O'Regan, 1984; van der Heijden et al., 1999). Van der Heijden and co-workers relate this tendency to saccadic eye movements, which bring a target into the fovea. From eye movement literature, it is well known that saccades are often too short by about $5 \%-10 \%$; to reach the target, the remaining distance is bridged by a corrective saccade or by a postsaccadic drift (see, e.g., Aitsebaomo \& Bedell, 1992; Bischof \& Kramer, 1968; Lemij \& Collewijn, 1989). This presumed relation to eye movements does not necessarily imply that the mislocalization is connected with the execution of saccades; as O'Regan has already shown, the foveal mislocalization is independent of whether the target presentation occurred before or after a saccade or during steady fixation. However, O'Regan's findings do not exclude an eye-movement-related extraretinal explanation. Even if, in order to keep fixation, eye movements are not executed, the eye movement tendencies may be sufficient to affect the localization of targets (see, e.g., Wolff, 1987).

The postulated relation between saccades and localization judgments is capable of accounting for the finding that the mislocalizations are only revealed with an asynchronous presentation of the comparison stimulus and the probe. The only assumption we have to add is that programming an eye movement takes time. Only then, does the observer come up with a first eye movement ten- 
dency to one stimulus and with a second tendency to the other. The distortion of the spatial map originates from the two different tendencies, with there being a larger foveal mislocalization for the spatially extended stimulus. If there is not sufficient time to program the second eye movement, the two stimuli are processed together, possibly eliciting only a single eye movement tendency. Then, they are represented in one common map with no- or at least no relative-distortion between them.

In addition to the "undershooting" that saccades and localization judgments apparently have in common, there are further correspondences between eye movements and localization behavior. Both eye movements and localization judgments become more precise with longer exposure durations (see, e.g., Abrams et al., 1989; Aitsebaomo \& Bedell, 1992; Kowler \& Blaser, 1995; Lemij \& Collewijn, 1989). Furthermore, the amplitude of saccades to targets depends on the grouping within a stimulus array; for example, if one element is made larger (Findlay, 1982), is made more intense (Deubel, Wolf, \& Hauske, 1984), or is presented with higher contrast (Deubel \& Hauske, 1988), the saccade lands closer to that target. The COG describes the perceived position of an array to which the eye is attracted (Findlay, Brogan, \& Wenban-Smith, 1993; see, also, Vos et al., 1993). The results of our Experiment 7 are in line with the COG effect. Our interpretation was that the salient square attracts processing - in a similar way as the COG-and that, therefore, either the inner or the outer edge has a disproportionate effect on the foveal mislocalization of the whole comparison stimulus. Thus, the only assumption we have to add is that the COG affects the foveal mislocalization. A last-but probably not least-important piece of evidence for a correspondence between eye movement behavior and the present relative localization judgment comes from the SOA variation in Experiment 2. The mislocalization emerges in an interval in which saccadic eye movements are programmed and executedthat is, typically between 50 and $200 \mathrm{msec}$.

Thus, our account of the foveal mislocalizations, albeit incomplete, derives directly from this presumed relation to eye movements. It is based on the assumption that the system in charge of the guidance of saccadic eye movements is also the system that provides the metric in perceived visual space (see Lotze, 1852, for an early example of this idea; see also, e.g., Koenderink, 1990; Wolff, 1987). According to this view, the system of sensation and eye movement organizes itself via an interaction with the environment that, after all, establishes spatial perception.

Of course, this view requires an explanation of why eye movements undershoot the target and, more critically, why the system does not adapt to this error. One might speculate that undershooting is an inherent property of any motor system, probably because it is easier to correct a movement in the same direction than in the opposite direction. Another argument would be that, with undershooting, the retinal image of the target remains in the same cortical hemifield, and the system need not switch to the other hemifield (see, e.g., Becker, 1972; Henson, 1978). A final possibility comes from considering more ecological conditions. Usually, targets do not enter the visual field instantaneously but appear in the visual field and move into it. Maybe saccadic undershooting anticipates this movement. This idea matches the observation that the system is more sensitive for foveofugal than for foveopetal movements (Mateeff et al., 1991; Müsseler \& Aschersleben, 1998).

An interesting problem to think about is whether perceived location determines saccade size or whether (intended, planned, programmed) saccade sizes (tendencies) determine perceived location. That problem is perhaps wrongly stated. The most parsimonious view is that perceived location is the saccade tendency and that saccade tendency is perceived location. The total of saccade tendencies $i s$, then, the total metric in visual space (Wolff, 1987).

\section{REFERENCES}

Abrams, R. A., Meyer, D. E., \& Kornblum, S. (1989). Speed and accuracy of saccadic eye movements: Characteristics of impulse variability in the oculomotor system. Journal of Experimental Psvchology: Human Perception \& Performance, 15, 529-543.

Adam, J. J., Ketelaars, M., Kingma, H., \& Hoek, T. (1993). On the time course and accuracy of spatial localizatıon: Basic data and a two-process model. Acta Psychologica, 84, 135-159.

Adam, J. J., PaAs, F. G. W. C., Ekering, J., \& van Loon, E. M. (1995). Spatial localization: Tests of a two-process model. Experimental Brain Research, 102, 531-539.

Aitsebaomo, A. P., \& Bedell, H . E. (1992). Psychophysical and saccadic information about direction for briefly presented visual targets. Vision Research, 32, 1729 -1737.

Averbach, E., \& Coriell., A. S. (1961). Short-term memory in vision. Bell System Technical Journal, 40, 309-328.

BADCoCk, D. R., \& Westheimer, G. (1985). Spatial location and hyperacuity: The centre/surround localization contribution function has two substrates. Vision Research, 25, 1259-1267.

BECKER, W. (1972). The control of eye movements in the saccadic system. In J. Dichgans \& E. Bizzi (Eds.), Cerebral control of eve movements and motion perception (pp. 233-243). Basel: Karger.

Bischof, N., \& KrAMER, E. (1968). Untersuchungen und Überlegungen zur Richtungswahrnehmung bei willkürlichen sakkadischen Augenbewegungen [Studies and considerations of the perception of direction during voluntary saccadic eye movements]. Psychologische Forschung, 32, 185-218.

BRIDGEMAN, B. (1998). Duratıons of stımuli displayed on video display terminals: $(\mathrm{n}-1) / \mathrm{f}+$ persistence. Psychological Science, 9, 232233

Deubel, H., \& Hauske, G. (1988). The programming of visually guided saccades. In H. Marko, G. Hauske, \& A. Struppler (Eds.), Processing structures for perception and action (pp. 119-132). Weinheım: DFG Sonderforschungsberichte, VCH Verlagsgesellschaft.

Deubel, H. Wolf, W., \& Hauske, G. (1982). Corrective saccades: Effect of shifting the saccade goal. Vision Research, 22, 353-364.

Deubel, H., Wolf, W., \& Hauske, G. (1984). The evaluation of the oculomotor error signal. In A. G. Gale \& F. Johnson (Eds.), Theoretical and applied aspects of eye movement research (pp. 55-62). Amsterdam: North-Holland.

Erkelens, C., Collewijn, H., \& Steinman, R. M (1989). Asymmetrical adaptation of human saccades to anisometropic spectacles. Investigative Ophthalmology \& Visual Science, 30, 1132-1145.

ERTSEY, S. (1997). Grundprozesse der Raumwahrnehmung: Absolute 
und relative Lokalisation von kurzzeitig präsentierten Reizen [Basics of space perception: Absolute and relative localization of briefly presented stimuli]. Unpublished master's thesis, University of Munich.

Festinger, L., Burnham, C., Ono, H., \& Bamber, D. (1967). Efference and the conscious experience of perception. Journal of Experimental Psychology, 74, 1-36.

FINDLAY, J. M. (1982). Global processing for saccadic eye movements. Vision Research, 22, 1033-1045.

FINDLAY, J. M. (1987). Visual computation and saccadic eye movements: A theoretical perspective. Spatial Vision, 2, 175-189.

Findlay, J. M., Brogan, D., \& Wenban-Smith, M. G. (1993). The spatial signal for saccadic eye movements emphasizes visual boundaries. Perception \& Psychophysics, 53, 633-641.

Finney, D. J. (1971). Probit analysis. Cambridge: Cambridge University Press.

Hagenatar, R., \& van der Hejuden, A. H. C. (1995). On the relation between type of arrays and type of errors in partial-report bar-probe studies. Acta Psychologica, 88, 89-104.

HAgEnaAR, R., \& VAN DER HEIJDEN, A. H. C. (1997). Location errors in partial-report bar-probe experiments: In search of the origin of cue-alignment problems. Memory \& Cognition, 25, 641-652.

Hagenzieker, M. P., van der Heijden, A. H. C., \& Hagenaar, R. (1990). Time courses in visual-information processing: Some empirical evidence for inhibition. Psychological Research, 52, 13-21.

HENSON, D. B. (1978). Corrective saccades: Effect of altering visual feedback. Vision Research, 18, 63-67.

KoEnderink, J. J. (1990). The brain a geometry engine. Psychological Research, 52, 122-127.

Kowler, E., \& BLASER, E. (1995). The accuracy and precision of saccades to small and large targets. Vision Research, 35, 1741-1754.

Lemij, H. G., \& CollewiJn, H. (1989). Differences in accuracy of human saccades between stationary and jumping targets. Vision Research, 29, 1737-1748.

LieBerman, H. R. (1983). Computation of psychophysical thresholds using the probit technique. Behavior Research Methods \& Instrumentation, 15, 446-448.

Lotze, H. (1852). Medizinische Psychologie oder Physiologie der Seele [Medical psychology or the physiology of the mind]. Leipzig: Weidmann.

Mack, A., Heuer, F., Villardi, K., \& Chambers, D. (1985). The dissociation of position and extent in Müller-Lyer figures. Perception \& Psychophysics, 37, 335-344.

Mateeff, S., \& Gourevich, A. (1983). Peripheral vision and perceived visual direction. Biological Cybernetics, 10, 111-118.

Mateeff, S., Yakimoff, N., Hohnsbein, J., Ehrenstein, W. H., BohDANECKY, Z., \& RADIL, T. (1991). Selective directional sensitivity in visual motion perception. Vision Research, 31, 131-138.

Mewhort, D. J. K., Campbell, A. J., Marchetti, F. M., \& Campbell, J. I. D. (1981). Identification, localization, and "iconic memory": An evaluation of the bar-probe task. Memory \& Cognition, 9, 50-67.

MüsSELER, J., \& ASCHERSLEBEN, G. (1998). Localizing the first position of a moving stimulus: The Fröhlich effect and an attention-shifting explanation. Perception \& Psychophysics, 60, 683-695.

O'Regan, J. K. (1984). Retinal versus extraretinal influences in flash localization during saccadic eye movements in the presence of a visible background. Perception \& Psychophysics, 36, 1-14.

OSAKA, N. (1977). Effect of refraction on perceived locus of a target in the peripheral visual field. Journal of Psychology, 95, 59-62.

Post, R. B., \& WELCH, R. B. (1996). Is there dissociation of perceptual and motor responses to figural illusions? Perception, 25, 569-581.
RaUK, M., \& LUUK, A. (1980). Identification and detection of spatial position in one-dimensional pattern. In Problems of cognitive psychology (Acta et Commentationes Universitatis Tartuensis: 522, pp. 143-163). Tartu State University, Department of Psychology.

REDDING, G. M., \& WALlaCE, B. (1992). Adaptive eye-hand coordination: Implications of prism adaptation for perceptual-motor organizatıon. In L. Proteau \& D. Elliott (Eds.), Vision and motor control (pp. 105-127). Amsterdam: North-Holland.

Rose, D., \& HALPERN, D. L. (1992). Stimulus mislocalization depends on spatial frequency. Perception, 21, 289-296.

SAARINEN, J. (1996). Localization and discrimination of "pop-out" targets. Vision Research, 36, 313-316.

ScotT, S. K. (1998). The point of P-centres. Psychological Research, 61, 4-11.

SkAVENSKI, A. A. (1990). Eye movement and visual localization of objects in space. In E. Kowler (Ed.), Eye movements and their role in visual and cognitive processes (pp. 263-287). Amsterdam: Elsevier.

SLOTNICK, R. S. (1969). Adaptation to curvature distortion. Journal of Experimental Psychology, 81, 441-448.

Treisman, A., \& Gormican, S. (1988). Feature analysis in early vision: Evidence from search asymmetries. Psychological Review, 95, 15 48 .

van der heijden, A. H. C., van der Geest, J. N., de Leeuw, F., KRIKKE, K., \& MÜsSELER, J. (1999). Sources of position-perception error for small isolated targets. Psychological Research, 62, 20-35.

Vos, P. G., Bocheva, N., Yakimoff, N., \& Helsper, E. (1993). Perceived location of two-dimensional patterns. Vision Research, 33, 2157-2169.

Westheimer, G. (1981). Visual hyperacuity. Progress in Sensory Physiology, 1, 1-30.

WolfF, P. (1987). Perceptual learning by saccades: A cognitive approach. In H. Heuer \& A. F. Sanders (Eds.), Perspectives on perception and action (pp. 249-271). Hillsdale, NJ: Erlbaum

\section{NOTE}

1. The duration of one vertical retrace corresponds to $14 \mathrm{msec}$ with the $71-\mathrm{Hz}$ monitor used in the experiments. Note, of course, that this duration does not reflect the exact presentation time. Within every vertical retrace, the pixels on the screen are illuminated one after the other, from the upper left to the lower right edge of the screen. Their illumination lasts only a few milliseconds (depending on the persistence of the monitor's phosphor); thus, with a typical commercial screen used in a white-on-black projection, the presentation time of one vertical retrace $r$ orresponds to an estimated duration of about $4 \mathrm{msec}$. However, the situation gets more complicated when a black-on-white projection is used, as in the present experiments. A dark stimulus is only established by the contrast with the surrounding bright pixels, which appear continuously only because of the human critical flicker fusion rate. In addition, the observer has no way to "detect" that a dark stimulus is present until the contrast appears in the retrace containing that stimulus (for further details, see, e.g., Bridgeman, 1998). Therefore, since the temporal constraints are less obvious in a black-on-white projection, all the presentation times of the present paper are given in the well-defined unit of one vertical retrace.

(Manuscript received March 3, 1998 ; revision accepted for publication November 2,1998 .) 